\title{
Marked Succession of Cyanobacterial Communities Following Glacier Retreat in the High Arctic
}

\author{
Igor S. Pessi ${ }^{1,2} \cdot$ Ekaterina Pushkareva $^{3} \cdot$ Yannick Lara ${ }^{1,4} \cdot$ Fabien Borderie $^{1,5} \cdot$ Annick Wilmotte $^{1} \cdot$ Josef Elster $^{3,6}$
}

Received: 16 June 2017 / Accepted: 8 May 2018 / Published online: 23 May 2018

(C) Springer Science+Business Media, LLC, part of Springer Nature 2018

\begin{abstract}
Cyanobacteria are important colonizers of recently deglaciated proglacial soil but an in-depth investigation of cyanobacterial succession following glacier retreat has not yet been carried out. Here, we report on the successional trajectories of cyanobacterial communities in biological soil crusts (BSCs) along a 100-year deglaciation gradient in three glacier forefields in central Svalbard, High Arctic. Distance from the glacier terminus was used as a proxy for soil age (years since deglaciation), and cyanobacterial abundance and community composition were evaluated by epifluorescence microscopy and pyrosequencing of partial 16S rRNA gene sequences, respectively. Succession was characterized by a decrease in phylotype richness and a marked shift in community structure, resulting in a clear separation between early (10-20 years since deglaciation), mid (30-50 years), and late (80100 years) communities. Changes in cyanobacterial community structure were mainly connected with soil age and associated shifts in soil chemical composition (mainly moisture, SOC, SMN, K, and Na concentrations). Phylotypes associated with early communities were related either to potentially novel lineages $(<97.5 \%$ similar to sequences currently available in GenBank) or lineages predominantly restricted to polar and alpine biotopes, suggesting that the initial colonization of proglacial soil is accomplished by cyanobacteria transported from nearby glacial environments. Late communities, on the other hand, included more widely distributed genotypes, which appear to establish only after the microenvironment has been modified by the pioneering taxa.
\end{abstract}

Keywords Cyanobacteria $\cdot$ Glacier forefield $\cdot$ High Arctic $\cdot$ High-throughput sequencing $\cdot$ Primary succession $\cdot$ Proglacial soil

Electronic supplementary material The online version of this article (https://doi.org/10.1007/s00248-018-1203-3) contains supplementary material, which is available to authorized users.

Igor S. Pessi

igor.pessi@gmail.com

1 InBioS - Centre for Protein Engineering, University of Liège, Allée du Six Août 13, B6a, Quartier Agora, Sart-Tilman, 4000 Liège, Belgium

2 Present address: Department of Microbiology, University of Helsinki, P.O. Box 56 (Viikinkaari 9), 00014 Helsinki, Finland

3 Centre for Polar Ecology, University of South Bohemia, Na Zlaté Stoce 3, 37005 České Budějovice, Czech Republic

4 Present address: UR Geology - Palaeobiogeology-PalaeobotanyPalaeopalynology, University of Liège, Allée du Six Août14, B18, Quartier Agora, Sart-Tilman, 4000 Liège, Belgium

5 Present address: Laboratoire Chrono-environnement, UMR 6249 CNRS Université Bourgogne Franche-Comté UsC INRA, Campus La Bouloie, Route de Gray 16, 25030 Besançon, France

6 Institute of Botany, Academy of Sciences of the Czech Republic, Dukelská 135, 37982 Třeboň, Czech Republic

\section{Introduction}

Most glaciers in the High Arctic have been retreating and thinning almost uninterruptedly since the end of the "Little Ice Age" (LIA) in the late nineteenth century [1]. Glacier retreat exposes new terrestrial and aquatic habitats which are readily colonized by pioneering organisms. This results in a spatiotemporal gradient of ecosystem development, where distance from the glacier terminus can be used as a proxy for time since deglaciation. This space-for-time substitution-also known as chronosequence - approach has been widely used to investigate the successional patterns of plant communities in glacier forefields [2]. Nevertheless, we know comparatively little about the earlier successional stages, prior to the establishment of plant communities, where microbial processes prevail.

Microorganisms are dominant in proglacial soil close to the glacier front, where low nutrient content and high levels of physical disturbance (e.g., glaciofluvial activity and frost weathering) preclude the establishment of larger organisms 
$[2,3]$. Cyanobacteria are typically recognized as common pioneers in these environments [4-6] and are often found in association with other bacteria, eukaryotic microalgae, fungi, and lichens forming complex communities known as biological soil crusts (BSCs) [7, 8]. Filamentous cyanobacteria such as Leptolyngbya, Phormidium, and Microcoleus have a pivotal role in BSC formation due to the production of extracellular polymeric substances (EPS), which promote the stabilization of the soil surface, moisture retention, and protection against erosion [7,9]. EPS protect the cells from the physical damages of desiccation and freezing and are thus a crucial adaptive feature enabling cyanobacteria to thrive in extreme conditions [10]. In many cyanobacteria, EPS sheaths are also rich in UVscreening pigments such as scytonemin, which protect the cells from the high UV radiation in the soil surface [11]. BSC cyanobacterial productivity is an important factor promoting the accumulation of organic matter in High Arctic ecosystems and constitutes the trophic foundation for other organisms [12]. It also facilitates the establishment of plant communities in later successional stages, at which point BSC cover declines due to increasing competition for nutrients, ground cover, and light [5, 13].

Insights into the successional dynamics of cyanobacterial communities in glacier forefields have been mostly limited to large-spectrum investigations targeting whole microbial communities, of which cyanobacteria are only a small fraction. These studies have shown that cyanobacteria are important components of proglacial soil communities in the High Arctic [14], Antarctica [15], the Swiss Alps [16-18], and the Peruvian Andes [19, 20]. Few works dedicated specifically to the study of cyanobacterial communities have so far been carried out, and these have mainly applied microscopic observations, culture-dependent, and/or traditional molecular fingerprinting techniques [21, 22]. High-throughput sequencing (HTS) allows the investigation of rare, low-abundance taxa and thus provides better estimations of microbial diversity in comparison to traditional techniques [23]. Moreover, phylumspecific community profiling has advantages over community-wide surveys as the use of universal primers can lead to under- or overrepresentation of specific groups [24]. HTS coupled with cyanobacteria-specific primers has recently been shown as a useful tool for the targeted assessment of cyanobacterial diversity in polar environments [25-28] but has not yet been applied to the investigation of cyanobacterial communities in glacier forefields.

A more thorough knowledge on how cyanobacteria respond to changing environmental conditions is key to better understand the effects of climate change on the functioning of polar ecosystems. The study of microbial succession in highlatitude ecosystems is of special interest given that deglaciated areas are likely to expand in the future according to general circulation models which predict enhanced warming in the Arctic [29]. Here, we provide an in-depth assessment of the successional trajectories of cyanobacterial communities in BSCs formed after the retreat of three glaciers in central Svalbard, High Arctic. By focusing on a short deglaciation gradient corresponding to 100 years of glacier retreat, we describe the early successional stages where vegetation cover is low and cyanobacteria are the most important primary producers. First, we were interested in determining if cyanobacterial communities undergo any discernible compositional shift along this short deglaciation gradient. We then set forth to investigate how shifts in community structure correlate with soil age and associated changes in soil chemical composition. Finally, we identify and further investigate the phylogenetic identity and biogeographic distribution of phylotypes associated with early and late communities in order to gain further insights into the dynamics of cyanobacterial communities following the colonization of recently deglaciated habitats.

\section{Materials and Methods}

\section{Study Area and Field Sampling}

The investigated glacier forefields are located in Petunia Bay $\left(78.68^{\circ} \mathrm{N}, 16.52^{\circ} \mathrm{E}\right)$, which is part of the northwestern branch of Billefjorden, central Spitsbergen, Svalbard archipelago (Fig. 1). The climate is typical of high-latitude environments with an annual mean air temperature of $-4.5^{\circ} \mathrm{C}$. The active growing season when liquid water is available typically lasts from midJune to early October and is characterized by a mean air temperature of $5{ }^{\circ} \mathrm{C}$. Wind circulation in Petunia Bay is influenced by the local topography, with strong katabatic winds from northeast and east along the Ragnar and Ebbabreen valleys, respectively, and southerly winds from Billefjorden [30].

Ebba $\left(78.73^{\circ} \mathrm{N}, 16.95^{\circ} \mathrm{E}\right)$ and Hørbyebreen $\left(78.76^{\circ} \mathrm{N}\right.$, $16.28^{\circ} \mathrm{E}$ ) are valley glaciers with marginal zones consisting of an ice front, and Ragnarbreen $\left(78.75^{\circ} \mathrm{N}, 16.70^{\circ} \mathrm{E}\right)$ is an outlet glacier terminating on land with a marginal lake. Bedrocks are composed of Carboniferous/Permian clastic (conglomerates, sandstones, and mudstones) and carbonate (limestones and dolomites) rocks [31]. Analysis of field measurements, topographical maps, aerial photography, and older scientific reports showed that Ebba, Hørbye, and Ragnarbreen currently present a negative mass balance and have lost, respectively, 5.2, 27.7, and $14.9 \%$ of their surface area from the end of the LIA until the early twenty-first century [32]. Glacier fronts have retreated a total of 1030,1525, and $1468 \mathrm{~m}$ during this period, at an average linear retreat rate of 10,15 , and $14 \mathrm{~m}$ year $^{-1}$, respectively [32].

Sampling was performed according to the chronosequence concept, in which distance from the glacier terminus is used as a proxy for soil age. Despite being an indirect approach, chronosequences are useful for studying mid- and long-term 


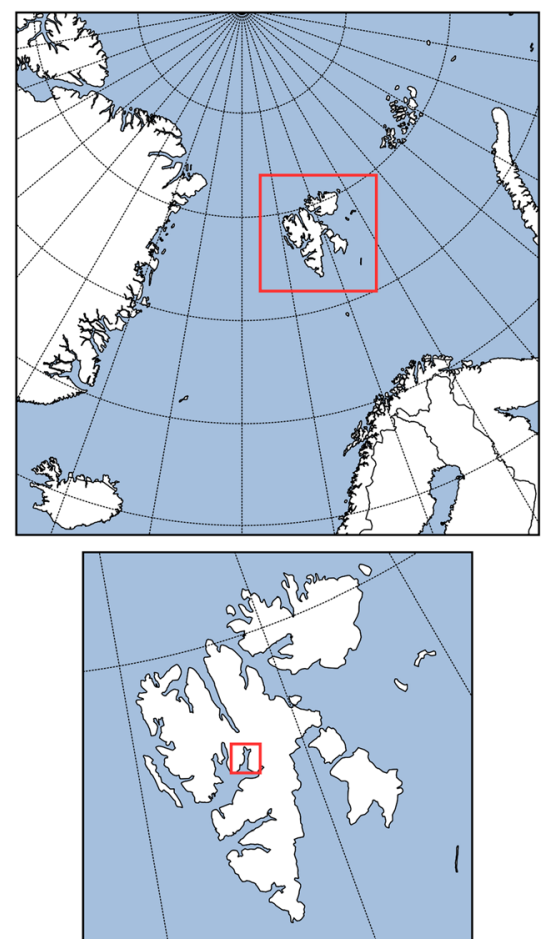

Fig. 1 Location of the Svalbard archipelago (top-left) and the Billefjorden region (bottom-left), and map of Petunia Bay showing the location of the sampling sites (right). A more detailed representation can

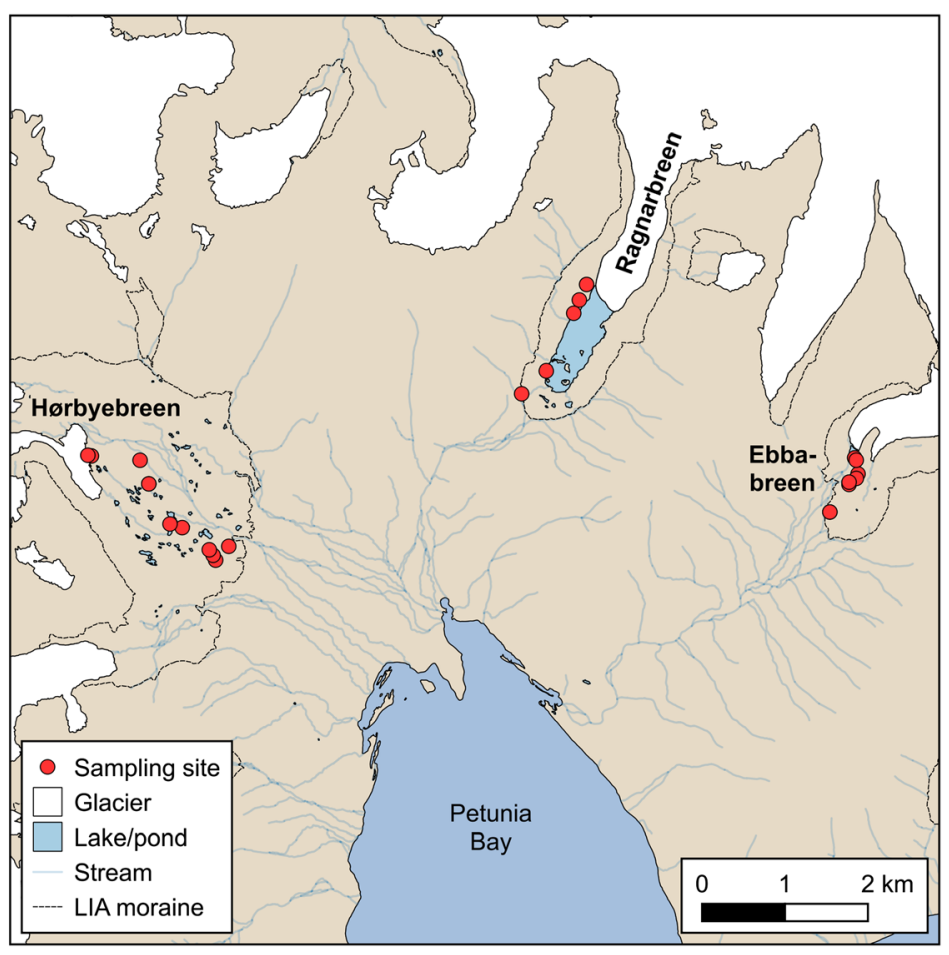

be found in Suppl. Fig. S1. Maps were created using open data from the Alaska Geobotany Centre (University of Alaska, Fairbanks, USA) and Norwegian Polar Institute (Tromsø, Norway)

Samples were put into plastic bags using a spatula and transported in dry ice to the laboratory, where they were kept at $-20{ }^{\circ} \mathrm{C}$ until processing.

\section{Determination of Soil Chemical Composition}

Soil chemical parameters were measured according to Czech Republic and European Union standards (ISO 10390, ISO 10523, ČSN EN 27888, ISO 11465, ČSN EN ISO 11732, ČSN EN ISO 13395, and ČSN EN ISO 15681-1). Moisture content was estimated after drying at $105^{\circ} \mathrm{C}$ for $6 \mathrm{~h}$. $\mathrm{pH}$ was measured in $1 \mathrm{M} \mathrm{KCl}$ solution (1:5) and conductivity in demineralized water (1:5). Soil organic carbon (SOC) content was measured by wet oxidation with acidified dichromate. Ammonium and nitrate concentrations were measured using a QuikChem 8500 Series flow injection analysis system (Lachat Instruments, Loveland, CO, USA). K, Na, Ca, and $\mathrm{Mg}$ contents were analyzed using a ContrAA atomic absorption spectrometer (Analytik Jena, Jena, Germany). The sum of ammonium and nitrate contents is expressed here as soil mineral nitrogen $(\mathrm{SMN})$.

\section{Estimation of Cyanobacterial Biovolume}

Cyanobacterial biovolume was determined using light and epifluorescence microscopy according to Kaštovská et al. [6]. Briefly, $1 \mathrm{~g}$ of sample was dissolved in $4 \mathrm{~mL}$ of distilled 
water and observed with a BX51 epifluorescence microscope (Olympus, Tokyo, Japan) equipped with a U-MWG filter cube (green excitation at 510-550 $\mathrm{nm}$ and emission at 590+ $\mathrm{nm}$ ). Cyanobacteria were discriminated according to their basic morphology into unicellular, heterocystous, and nonheterocystous filamentous morphotypes, and geometric equations were applied in order to calculate the biovolume of each morphological group [33].

\section{Assessment of Cyanobacterial Diversity}

Cyanobacterial community composition was investigated by pyrosequencing of partial 16S rRNA gene sequences according to Pessi et al. [26]. In summary, DNA was extracted in duplicates from ca. $0.5 \mathrm{~g}$ of sample using the PowerSoil DNA Isolation Kit (MOBIO, Carlsbad, CA, USA). DNA extracts were pooled and partial 16S rRNA gene sequences were obtained by PCR using the primer set CYA359F and CYA781Ra/CYA781Rb, which amplifies the V3-V4 region of the cyanobacterial 16S rRNA gene [34]. PCR reactions were performed in triplicates in order to minimize the influence of amplification biases. These were pooled and purified using the GeneJet PCR Purification Kit (ThermoScientific, Waltham, MA, USA). Sequencing was performed using the 454 GS FLX+ Titanium platform (454 Life Sciences, Branford, CT, USA) at the Beckman Coulter Genomics facilities (Danvers, MA, USA).

Quality control of reads, removal of chimeric sequences, and operational taxonomic unit (OTU) clustering were performed using UPARSE [35] according to Pessi et al. [26]. Briefly, two and zero mismatches were allowed to the primer and barcode sequences, respectively, and reads were required to have a maximum expected error of 0.5 and a length of $370 \mathrm{bp}$ after the removal of primer and barcode sequences. Quality-filtered sequences were clustered into OTUs at the 97.5\% similarity threshold, which corresponds to $97.0 \%$ similarity over the full length of the cyanobacterial $16 \mathrm{~S}$ rRNA gene [36]. OTUs were classified using CREST [37] based on the Greengenes database [38], which follows the suprageneric classification of Hoffmann et al. [39]. In this system, filamentous non-heterocystous cyanobacteria are included in the orders Pseudanabaenales (comprising generally thin filamentous taxa with parallel thylakoids such as Leptolyngbya and Pseudanabaena) and Oscillatoriales (larger filamentous taxa with radial thylakoids such as Microcoleus and Phormidium). Unicellular taxa are assigned to the orders Gloeobacterales (no thylakoids), Synechococcales (parallel thylakoids), and Chroococcales (radial thylakoids). Finally, all heterocystous taxa are grouped in a single order, the Nostocales. Non-cyanobacterial OTUs-consisting of sequences assigned to plastids of eukaryotic phototrophs (3.6\% of quality-filtered sequences) and other bacterial phyla such as Acidobacteria, Chloroflexi, and TM7 (0.5\%)—were removed from the dataset.

\section{Statistical and Phylogenetic Analyses}

Downstream analyses were carried out after a normalization step based on subsampling the pyrosequencing dataset to 1393 sequences per sample. Significant shifts in soil chemical composition, cyanobacterial biovolume, and phylotype richness along the deglaciation gradient were assessed by simple linear regression using STATISTICA 12 (StatSoft, Tulsa, OK, USA).

Beta diversity analyses were performed in PRIMER 7 (Primer-E, Plymouth, UK). This did not include samples from Ragnarbreen, which were removed due to a lack of spatial replication. Community dissimilarities were computed based on unweighted UniFrac distances [40] using QIIME [41]. The overall variability in community structure within each forefield was first examined using unweighted pair group method with arithmetic mean (UPGMA) and principal coordinates (PCO) analyses. Based on the observed clustering patterns, samples were then categorized into three community groups according to soil age (early, 10-20 years since deglaciation; mid, 30-50 years; and late, 80-100 years). Significant differences between soil age community groups were evaluated using permutational ANOVA (PERMANOVA) [42] and canonical analysis of principal coordinates (CAP) [43].

A combination of distance-based linear models (distLMs) and variation partitioning [44] was used to determine the amount of variation in community structure which could be attributed to soil age and differences in soil chemical composition. Prior to the analyses, predictor variables were $\log (x+1)$ transformed (except $\mathrm{pH}$ ) and standardized by subtracting the mean and dividing by the standard deviation of the variable. First, a model building with forward selection based on the adjusted $\mathrm{R}^{2}$ criterion and 1000 permutations was used to select a subset of soil chemical parameters which best explain the variation in community structure. These were included along with soil age in a new distLM routine combined with variation partitioning to distinguish between the amount of variation explained by (i) the selected soil chemical variables, (ii) soil age, and (iii) both sets of factors combined.

Pearson correlation between OTU distribution data and the CAP axes was used to identify phylotypes associated with each community group observed in the clustering analysis (referred to as "indicator phylotypes"), which were submitted to further phylogenetic and biogeographic analyses. A representative sequence was selected for each indicator phylotype as being the most abundant unique sequence in the cluster. In order to verify their current biogeographic distribution, all closely related ( $\geq 97.5 \%$ similarity) cultured and uncultured sequences were retrieved from GenBank using BLAST, and information relative to the source and country of isolation of 
each hit was obtained using in-house bash scripts. For phylogenetic analyses, indicator phylotypes were aligned using MUSCLE [45] along with their closest BLAST isolate hits. A maximum likelihood tree based on the Kimura 2-parameter model was then computed using MEGA 7 [46].

\section{Sequence Data}

Raw sequencing data are available in the NCBI Sequence Read Archive (SRA) database under the accession numbers SRR5382144-SRR5382167.

\section{Results}

\section{Cyanobacterial Communities Are Dominated by Filamentous Taxa}

A total of 294,469 pyrosequencing reads with an average length of $410 \mathrm{bp}$ were obtained (average of 12,269 sequences per sample). After removal of low-quality, chimeric, and noncyanobacterial sequences, 152,541 sequences $(51.8 \%$ of the initial pyrosequencing reads) were grouped into 148 OTUs at $97.5 \%$ similarity. Cyanobacteria were the most dominant phototrophs, with plastid sequences from eukaryotic organisms accounting for only $3.6 \%$ of the quality-filtered reads. Pseudanabaenales was the most phylotype-rich order (96 OTUs), followed by Chroococcales (13 OTUs), Oscillatoriales (7 OTUs), Synechococcales (6 OTUs), Nostocales (5 OTUs), and Gloeobacterales (3 OTUs). Eighteen OTUs were not classified by CREST at the order level, as well as most phylotypes at the genus level (118 OTUs). Phylotypes which could be successfully classified at this taxonomic level were assigned to the genera Leptolyngbya (21 OTUs), Phormidium (3 OTUs), Nostoc, Pseudanabaena (2 OTUs each), Chroococcidiopsis, and Microcoleus (1 OTU each).

In Ebba and Hørbyebreen, communities were largely dominated by sequences from non-heterocystous filamentous cyanobacteria (Pseudanabaenales and Oscillatoriales; sensu Hoffmann et al. [39]), which comprised together 96.8$99.9 \%$ of the quality-filtered reads in each sample (Fig. 2a). Unicellular and heterocystous cyanobacteria accounted for only a minor part of the communities $(0.1-2.2$ and $0.1-1.7 \%$ of the reads, respectively). Community structure differed slightly in Ragnarbreen, where unicellular and heterocystous cyanobacteria reached higher relative abundances in some samples (up to 6.5 and $25.2 \%$ of the reads, respectively). In contrast to the pyrosequencing analysis, biovolume estimations evidenced a higher proportion of unicellular and heterocystous cyanobacteria, which comprised up to 59.4 and $43.9 \%$ of the total cyanobacterial biovolume in some samples, respectively (Fig. 2b).

\section{Nutrients and Cyanobacterial Abundance Increase with Soil Age}

Soil chemical composition fluctuated considerably along the soil age gradient, but a weak increasing trend was observed for some parameters (Suppl. Fig. S2). SOC content shifted from $16.5-45.3 \mathrm{~g} \mathrm{~kg}^{-1}$ in early (10-20 years since deglaciation) to $28.4-52.0 \mathrm{~g} \mathrm{~kg}^{-1}$ in late (80-100 years) samples $(r=0.29, p=$ $0.02)$. SMN content increased steadily from $0.8-3.5$ to 2.0 $4.3 \mathrm{mg} \mathrm{kg}^{-1}$ in early and late samples, respectively $(r=0.58$, $p=0.01)$. Weak increasing trends were also observed for $\mathrm{pH}$, $\mathrm{K}, \mathrm{Na}$, and $\mathrm{Mg}(r=0.46-0.57, p<0.05)$. Finally, total cyanobacterial biovolume fluctuated substantially but also displayed a weak increasing trend $(r=0.40, p=0.05$; Suppl. Fig. S2).

\section{Cyanobacterial Community Structure Shifts with Soil Age and Associated Changes in Soil Composition}

Due to differences in sequencing depth between samples (Suppl. Fig. S3), alpha and beta diversity analyses were performed after subsampling the dataset to an even depth of 1393 cyanobacterial sequences per sample. Cyanobacterial phylotype richness decreased with increasing soil age, from 33 to 49 OTUs in early (10-20 years since deglaciation) to $22-42$ OTUs in late (80-100 years) samples $(r=-0.53, p=0.02)$. Cyanobacterial community structure also shifted significantly, with beta diversity analyses discriminating between three general community types according to soil age in the Ebba and Hørbyebreen forefields (Fig. 3, Suppl. Fig. S4). Early (10-20 years), mid (30-50 years), and late communities ( $80-100$ years) formed well-defined groups and were significantly distinct from each other (PERMANOVA; pseudo-F $=1.84$, $p=0.02$ ). This was also confirmed by the CAP procedure, which was carried out taking both forefields together (Fig. 4). The canonical correlations for the two produced axes was high $\left(\delta_{1}=0.98\right.$ and $\left.\delta_{2}=0.74\right)$, and a significant separation between community types was observed along the first axis $\left(\delta_{1}^{2}=0.90, p=0.05\right)$.

Among soil chemical parameters, moisture, SOC, SMN, K, and $\mathrm{Na}$ were the best predictors of community structure, accounting together for $35.8 \%$ of the variation (distLM; pseudo$\mathrm{F}=1.45, p=0.04)$. When considered alone, soil age explained $14.1 \%$ of the variation (pseudo-F $=2.80, p<0.01$ ). The complete model, computed using variation partitioning analysis with both sets of factors, accounted for $46.9 \%$ of the variation. Of these, $32.8 \%$ were uniquely explained by the selected soil chemical variables (pseudo- $\mathrm{F}=1.48, p=0.03$ ) and $11.1 \%$ by soil age (pseudo- $\mathrm{F}=2.49, p=0.01$ ). The remaining explained variation $(3.0 \%)$ was accounted for by the combination of both sets of factors. 
Fig. 2 Cyanobacterial community structure along the soil age gradient as observed by a 454 pyrosequencing of $16 \mathrm{~S}$ rRNA gene sequences and $\mathbf{b}$ epifluorescence microscopy. Suprageneric classification of 454 pyrosequencing reads was carried out following the taxonomic system of Hoffmann et al. [39]
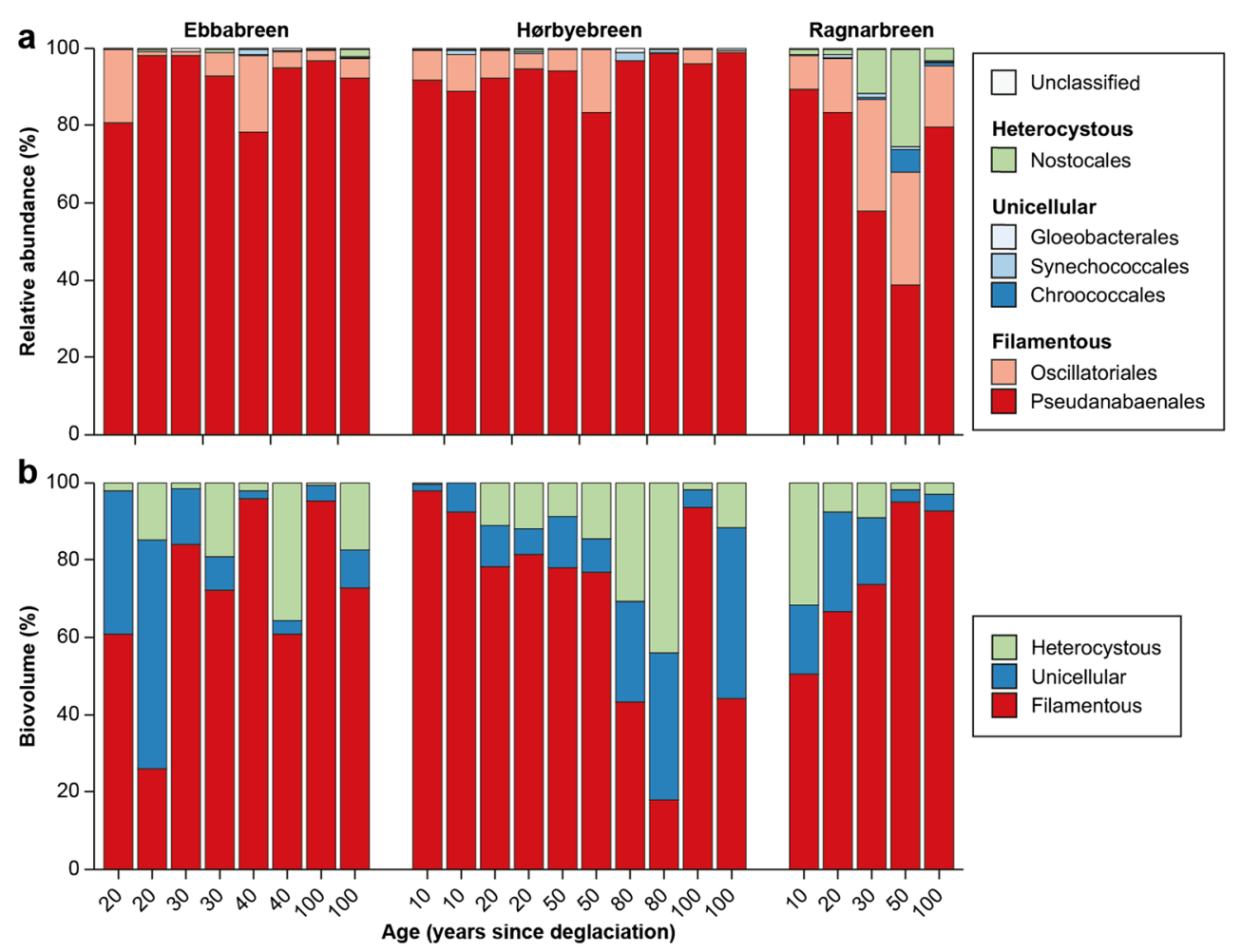

\section{Early Colonizers Are Mainly Related to Novel and Polar/Alpine Cyanobacteria}

Pearson correlation between OTU distribution data and the CAP axes identified 24 OTUs associated with a given soil age community group (i.e., indicator phylotypes) in the Ebba and Hørbyebreen forefields (Fig. 4). Among the 16 OTUs associated with early and mid communities, 10 OTUs had no closely related ( $\geq 97.5 \%$ similarity) sequences in GenBank and thus likely represent novel cyanobacterial lineages (OTUs 58, 79, 83, 114, 115, 117, 150, 165, 179, and 211; Fig. 5). Their best GenBank hits included several Leptolyngbya antarctica, Leptolyngbya frigida, and Phormidesmis priestleyi strains isolated from Antarctic lakes [47] but with very low sequence similarity (92.6-96.4\%). Remaining early/mid phylotypes were most closely related to $P$. priestleyi ANT.LG2.4 (OTU7, 100.0\% similarity), $P$. priestleyi ANT.L66.1 (OTU126 and OTU222, 97.5-97.8\% similarity), and Phormidium sp. CYN64 (OTU8, 98.9\% similarity), all isolated from Antarctic lakes [47, 48]. OTU31 and OTU122, associated with mid communities only, were related (97.5-98.9\% similarity) to different strains of Leptolyngbya, including L. antarctica ANT.LAC.1 isolated from Ace Lake (Antarctica) [47]. BLAST analysis taking into account all closely related $(\geq 97.5 \%$ similarity) cultured and uncultured sequences from GenBank revealed that phylotypes associated with early/mid communities have restricted biogeographic distributions (Fig. 5). For each phylotype, the vast majority (75.5-100.0\%) of BLAST hits consisted of sequences retrieved from polar and alpine regions, including proglacial soil, lacustrine microbial mats, and supraglacial habitats such as glacier snow and cryoconite holes.

The eight phylotypes associated with late communities, on the other hand, had a much wider geographic distribution. A high proportion (up to $73.1 \%$ ) of the BLAST hits for these phylotypes consisted of sequences coming from non-polar environments, which, in most cases, also included their closest isolate hit (Fig. 5). For example, OTU30 was most closely related ( $97.5 \%$ similarity) to Leptolyngbya sp. FYG isolated from a hot spring in the Yellowstone National Park (USA) [49], and OTU18 was $97.8 \%$ similar to Oscillatoria geminata SAG 1459-8 isolated from a factory cooling tower in Germany (Friedl et al., unpublished). OTU17 and OTU38 were related (97.8-99.2\% similarity) to two Leptolyngbya sp. strains (LEGE 07074 and LEGE 07075) isolated from Portuguese estuaries [50]. Finally, OTU155 was related to Gloeobacter kilaueensis JS1 isolated from a lava cave in Hawaii [51], although with very low sequence similarity $(94.8 \%)$.

\section{Discussion}

Ecological succession is one of the oldest topics in modern ecology dating back to the end of the nineteenth century but has been, until recently, overwhelmingly limited to the study of plant communities [2]. Studies of microbial succession in glacier forefields are much more recent [3]. Here, we focus on 
Fig. 3 Principal coordinates analysis (PCO) of 16S rRNA gene assemblages in $\mathbf{a}$ Ebba and $\mathbf{b}$ Hørbyebreen. Dashed circles represent UPGMA groups (see Suppl. Fig. S4)
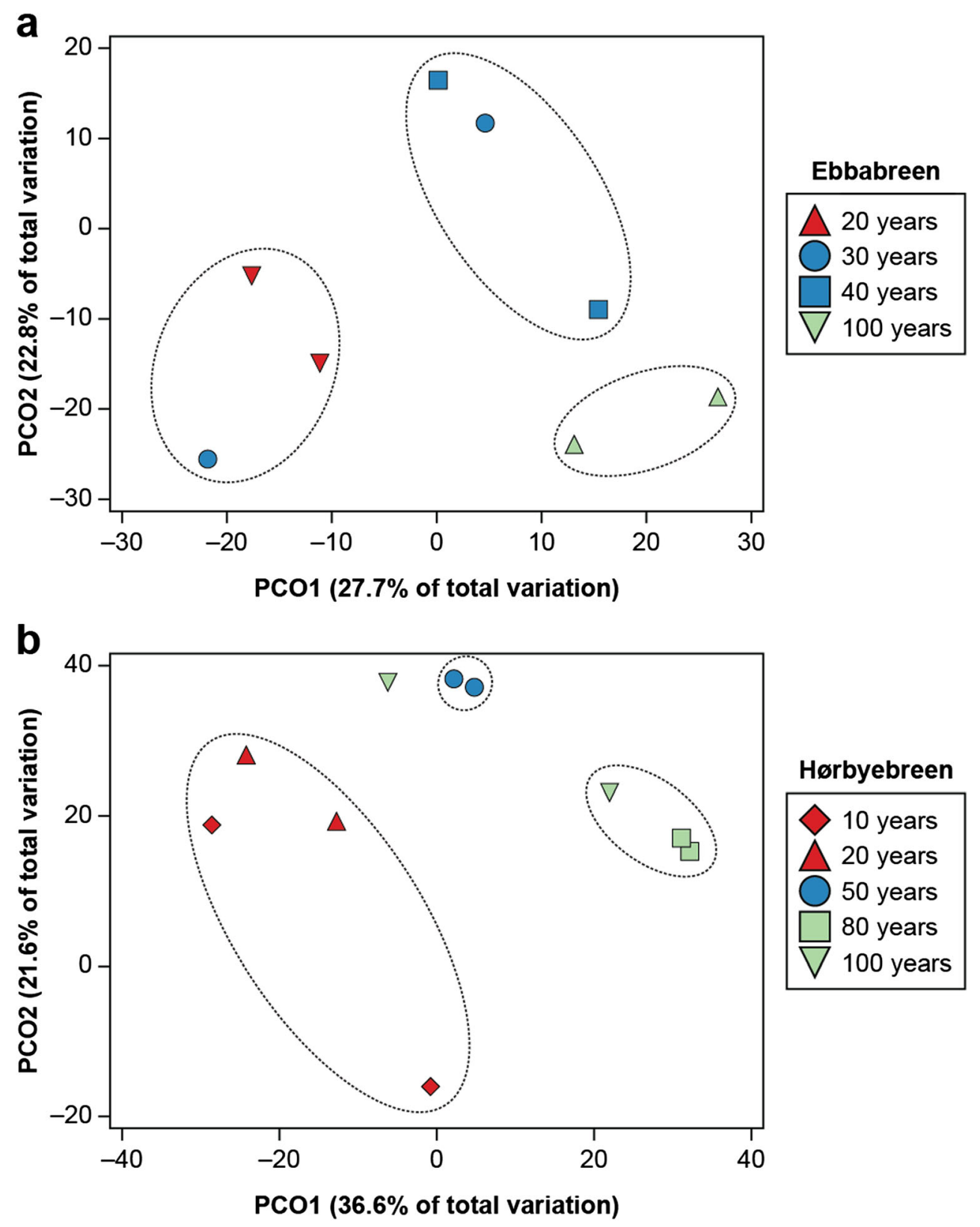

the cyanobacteria-one important microbial group in proglacial soils worldwide [4] — and provide an in-depth overview of their successional trajectories in three glacier forefields in central Svalbard, High Arctic (Fig. 1). Despite the rather short deglaciation gradient contemplated in this study (100 years of glacier retreat), frequent disturbance events [2], and the patchy distribution of soil microorganisms [52], our results evidence marked and consistent shifts in cyanobacterial community structure with increasing soil age (Figs. 3 and 4). Cyanobacterial succession was partially associated with minor increases in soil nutrient content. Early colonizers were either potentially novel $(<97.5 \%$ similar to sequences currently available in GenBank) or related to lineages of $P$. priestleyi and $L$. antarctica largely restricted to cold biosphere habitats such as proglacial soil, supraglacial snow, and cryoconite holes. Late communities, on the other hand, included phylotypes with a much wider cosmopolitan distribution, being related to sequences also retrieved from temperate and even tropical regions (Fig. 5).

Both molecular and morphological analyses confirmed the role of filamentous cyanobacteria as important components of proglacial soil ecosystems (Fig. 2), in agreement with previous investigations of cyanobacterial diversity in polar and alpine glacier forefields [6, 21, 22]. Leptolyngbya-, Phormidium-, and Microcoleus-like morphotypes are the main representatives of filamentous non-heterocystous cyanobacteria in BSCs worldwide, including in the High Arctic $[4,7,8]$. They contribute vastly to the stabilization of 


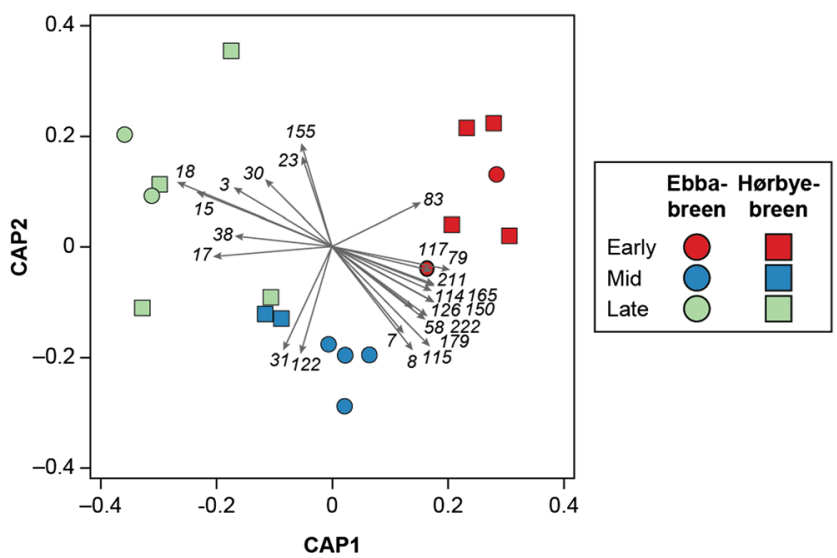

Fig. 4 Canonical analysis of principal coordinates (CAP) ordination of 16S rRNA gene assemblages in Ebba and Hørbyebreen. Cyanobacterial communities were classified as early (10-20 years since deglaciation), mid ( $30-50$ years), and late ( $80-100$ years) according to Fig. 3. Overlaid arrows represent phylotypes associated with each community group

the soil surface due to the production of high amounts of EPS, which protect them from the physical damages of desiccation and freeze-thaw cycles [7, 9]. Unlike smaller unicellular taxa, large filamentous cyanobacteria such as Phormidium and Microcoleus have high mobility, which helps them to persist during the earlier successional stages where physical disturbances are frequent and substrate instability is high [7]. Despite an overall dominance of non-heterocystous filamentous cyanobacteria based on 16S rRNA gene sequences obtained by pyrosequencing (Fig. 2a), epifluorescence microscopy analysis showed that heterocystous and unicellular cyanobacteria are also an integral part of the investigated communities (Fig. 2b). Heterocystous cyanobacteria from the order Nostocales are common in proglacial soils worldwide [6, 19-22], where they likely play an important role in the accumulation of organic matter due to their ability to fix atmospheric nitrogen $[2-4,53]$. Unicellular cyanobacteria, on the other hand, are in general not commonly found in poorly developed polar BSCs due to their low mobility $[7,8]$. The high abundance of unicellular forms observed by microscopy in the present study can be attributed to difficulties in performing biovolume estimations for soil samples. The need to apply harsh grinding to break down soil particles also results in the disintegration of colonies of unicellular cyanobacteria, thus potentially overestimating their abundance [28]. Molecular methods also have weaknesses of their own. For instance, the DNA extraction step is an important source of bias in molecular investigations of cyanobacterial assemblages, as high amounts of EPS in the biofilm matrix interfere considerably with cell lysis procedures [54]. Moreover, using data from artificial communities, Pessi et al. [26] showed that PCR and sequencing biases shift considerably the observed relative abundances of individual cyanobacterial taxa. Microscopic analyses, on the other hand, provide little or no taxonomic information beyond discriminating between major cyanobacterial groups, as the relatively simple morphology of many taxa complicates identification at lower taxonomic levels [55]. Thus, the parallel application of both molecular and microscopy methods seems a valuable approach for assessing cyanobacterial community structure at different taxonomic levels.

Our results suggest that cyanobacteria involved in the early colonization of proglacial soil have a marked polar characteristic (Fig. 5). It has been proposed that pioneering microorganisms comprise usually cosmopolitan taxa, since they are fundamentally more widely dispersed and thus have higher chances of colonizing remote habitats [56]. Nevertheless, it is likely that the harsh environmental conditions found in proglacial soil preclude the establishment of cosmopolitan, generalist taxa. Polar cyanobacteria, on the other hand, possess several structural and physiological adaptations which enable them to withstand harsh environmental conditions, as it has been recently shown for $P$. priestleyi strains isolated from a cryoconite hole in Greenland and a lacustrine microbial mat in Antarctica [57, 58]. In addition, cyanobacteria are abundant members of the microbial communities in a range of polar ecosystems. For example, they make up an important fraction of supraglacial communities [59-61], which provide an important supply of inoculi and nutrients to downstream habitats via glacial runoff [62]. Vonhamme et al. [61] showed that filamentous cyanobacteria such as Phormidium and Leptolyngbya are particularly abundant in cryoconite sediments on Svalbard glaciers, including Hørbye and Ebbabreen. Indeed, mat-forming filamentous cyanobacteria are among the most abundant cyanobacteria in cryoconite holes worldwide [59]. Thus, it appears that cyanobacteria thriving in supraglacial habitats have a pivotal role in the initial colonization of recently deglaciated forefield soils. In a recent study in the Damma glacier forefield (Swiss Alps), Rime et al. [18] showed that bacterial communities in newly exposed soils are similar to those in sub- and supraglacial sediments and significantly different from communities in snow and atmospheric deposition. Our findings are in line with these observations and highlight the importance of endogenous habitats as a source of propagules for downstream environments.

In contrast with early communities, which appear to be enriched in polar cyanobacteria transported from nearby supraglacial habitats, more advanced communities included phylotypes with wider, cosmopolitan distributions (Fig. 5). As shown by the distLM analysis, changes in cyanobacterial community structure were partially associated with shifts in soil chemical composition, mainly increases in moisture, SOC, SMN, K, and Na content. This is in agreement with previous reports for other polar and alpine glacier forefields $[14,16,17,19,20,22]$, although rather weak increasing trends were observed for most parameters in the present study (Suppl. Fig. S2). There is a wide consensus concerning the 
Fig. 5 Phylogenetic and biogeographic analyses of phylotypes associated with early/ mid communities (red), mid communities only (blue), and late communities (green). Maximum Likelihood tree of phylotypes and their most closely related isolate sequence in GenBank. Bar plots show the biogeographic distribution of the phylotypes based on the geographic origin of all closely related $(\geq 97.5 \%$ similarity) sequences retrieved from GenBank. ARC Arctic, ANT Antarctic, ALP alpine, W world

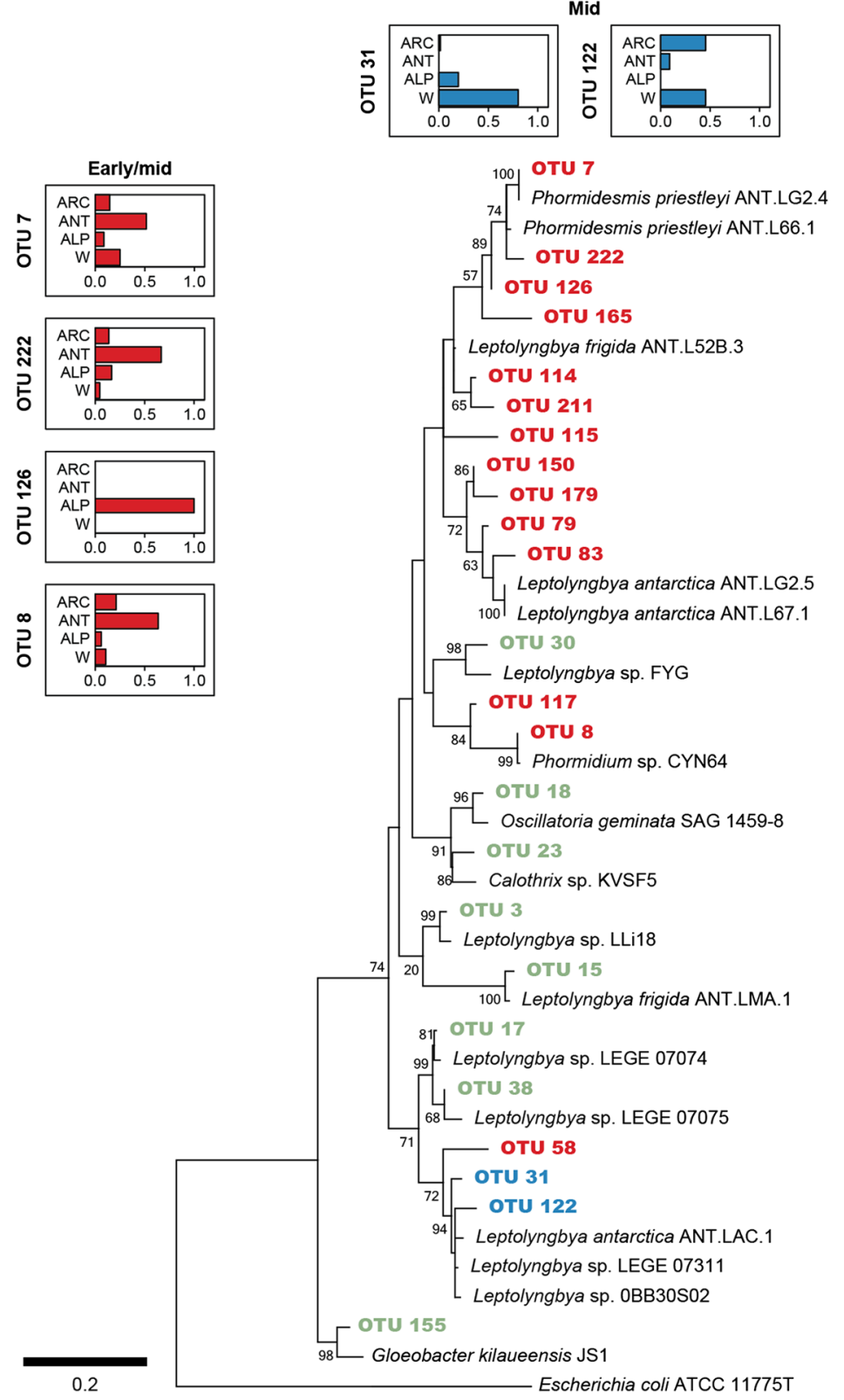

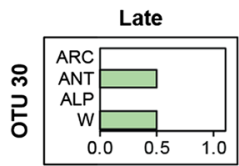
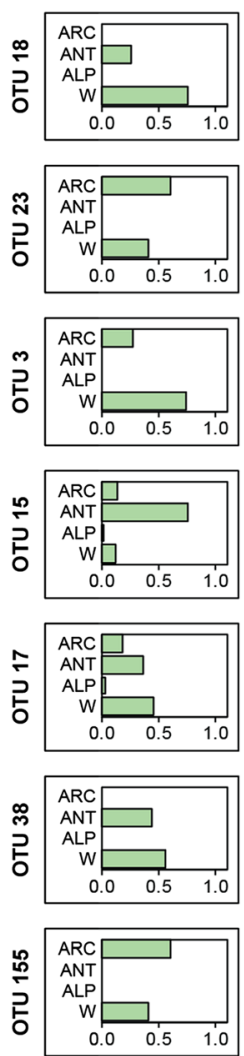

importance of cyanobacterial production for organic matter accumulation in proglacial soil ecosystems [2, 4, 5, 12]. Nevertheless, in addition to autotrophic production, microbial communities are also maintained by inputs of nutrients from allochtonous sources (e.g., through aerial deposition and runoff from the glacier surface) and ancient organic pools [53]. In any case, other studies have shown that BSC development and succession are tightly linked to soil physicochemical properties [7, 9]. For example, changes in cyanobacterial community structure along a gradient of BSC development in the High Arctic have been attributed to shifts in $\mathrm{pH}$, conductivity, moisture, and SOC content [25]. Thus, it appears that the somewhat milder microenvironment in later successional stages facilitates the establishment of more widely distributed taxa.
This new microenvironment is characterized not only by higher nutrient content as discussed above but also by improved structural conditions brought about by the consolidation of BSC communities (e.g., increased soil stability and protection against physical damages due to higher amounts of EPS in the biofilm matrix) [7]. Here, the pioneering, polar cyanobacteria, which are favored in the earlier stages where population densities and competition levels are low, appear outcompeted by cosmopolitan taxa since the latter are, by definition, adapted to a wider range of environmental conditions.

In agreement with previous studies of microbial succession [3], as well as with the general consensus regarding microbial community assembly $[52,56]$, shifts in community structure 
were mostly associated with changes in the soil microenvironment. In addition to the expected effect of soil chemical composition, changes in cyanobacterial community structure were also associated with soil age. Even though care was taken in order to include the most relevant edaphic parameters, it is possible that the observed relationship between soil age and community structure might be partially attributed to other unmeasured biotic and abiotic variables. For example, mechanical disturbances and surface instability have a major impact on BSC composition and succession [7, 12, 13]. This is likely more pronounced in earlier stages, as soil stability is higher in later successional stages due to the protective effect of EPS produced by BSC cyanobacteria [7]. The observed correlation between community structure and soil age might also represent the effects of historical processes, as proposed by Freedman and Zak [63] for a long-term chronosequence in the Upper Great Lakes Region (USA). The authors found that shifts in bacterial community structure were explained by both environmental (53\%) and temporal (17\%) factors and attributed the latter to lingering effects from historical events (associated with, for example, ecological drift and dispersal limitation), which are known to influence present-day microbial assemblages [52]. In agreement with the aforementioned study, our results suggest a role of historical events in shaping the successional trajectories of cyanobacterial communities in glacier forefields. We further suggest that dispersal limitation is an important factor particularly in the earlier successional stages, as microorganisms inhabiting upstream glacial habitats would have preferential access to the newly formed proglacial environment. As discussed above, the initial colonization of glacier forefield soil appears to be achieved by local propagules transported from the glacier surface via glacial runoff or through the action of katabatic winds which blow from the glacier plateau towards the valley. As succession progresses, dispersal limitation likely becomes less important, as the longer the newly formed soil environment has been exposed, the more likely is the establishment of propagules arriving from remote habitats.

The model of cyanobacterial succession described above is, in many ways, similar to the traditional knowledge on primary succession resulted from the study of plant communities in glacier forefields [2]. For example, studies at Glacier Bay, Alaska, have shown that pioneering plants associated with nitrogen-fixing bacteria increase the soil nitrogen levels and facilitate the establishment of late successional trees [64, 65]. Furthermore, patterns of plant succession are usually linked to differences in life history between early and late colonizers, i.e., characteristics related to reproduction, life span, and dispersal [2]. For plants and microorganisms alike, pioneering species are usually specialists (R-strategists), while later successional taxa are usually generalists (K-strategists) $[2,66,67]$. Similarly, our results suggest that pioneering cyanobacteria comprise specialized, polar taxa such as $P$. priestleyi, which have evolved structural and physiological characteristics suitable for dispersal and growth in harsh polar environments $[57,58]$. Their activity and growth increase the soil nutrient status, stability, and protection against physical damages, which facilitate the establishment of more generalist, cosmopolitan taxa later in succession.

In conclusion, our results confirm the role of cyanobacteria as important pioneers and the main phototrophs in recently deglaciated forefield soil. Likely as a result of changes in the soil nutrient status, succession was characterized by a decrease in phylotype richness and a marked shift in community structure. Early colonization of proglacial soil seems to be accomplished by polar cyanobacteria likely transported from nearby glacial environments, which (i) have easy and rapid access to the newly formed habitats, (ii) are structurally and physiologically adapted to the severe environment, and (iii) benefit from low competition levels. Pioneering organisms, in turn, modify the microenvironment by increasing nutrient levels, soil stability, and protection against physical damages, enabling the establishment of more widely distributed taxa later in the succession. To the best of our knowledge, this study represents the first in-depth assessment of cyanobacterial succession in High Arctic glacier forefields. It adds to the body of evidence that microbial communities undergo remarkable succession following glacier retreat and contributes for a better understanding of the functioning and evolution of polar ecosystems.

Acknowledgements IS Pessi is a PhD FRIA fellow and A Wilmotte is a Research Associate of the FRS-FNRS. The authors would like to thank J Kavan for the help setting up the sampling strategy and L Cappelatti, HD Laughinghouse IV, PB Costa, E Verleyen, A Corato, T Gerards, and F Franck for the valuable suggestions and discussion.

Funding information This work was supported by the Ministry of Education, Youth, and Sports of the Czech Republic (grants LM2010009 and RVO67985939) and the Belgian National Fund for Scientific Research (FRS-FNRS) under the projects PYROCYANO (grant CRCH1011-1513911) and BIPOLES (grant FRFC2457009).

\section{References}

1. Dowdeswell JA, Hagen JO, Björnsson H, Glazovsky AF, Harrison WD, Holmlund P, Jania J, Koerner RM, Lefauconnier B, Ommanney CSL, Thomas RH (1997) The mass balance of circum-Arctic glaciers and recent climate change. Quat Res 48:114. https://doi.org/10.1006/qres.1997.1900

2. Matthews JA (1992) The ecology of recently-deglaciated terrain: a geoecological approach to glacier forelands and primary succession. Cambridge University Press, Cambridge

3. Bradley JA, Singarayer JS, Anesio AM (2014) Microbial community dynamics in the forefield of glaciers. Proc R Soc B 281: 20140882. https://doi.org/10.1098/rspb.2014.0882

4. Elster J (2002) Ecological classification of terrestrial algal communities in polar environments. In: Beyer L, Bölter M (eds) Geoecology of Antarctic ice-free coastal landscapes. SpringerVerlag, Berlin, pp 303-326 
5. Hodkinson ID, Coulson SJ, Webb NR (2003) Community assembly along proglacial chronosequences in the high Arctic: vegetation and soil development in north-west Svalbard. J Ecol 91:651-663. https://doi.org/10.1046/j.1365-2745.2003.00786.x

6. Kaštovská K, Elster J, Stibal M, Šantrůčková H (2005) Microbial assemblages in soil microbial succession after glacial retreat in Svalbard (High Arctic). Microb Ecol 50:396-407. https://doi.org/ 10.1007/s00248-005-0246-4

7. Büdel B, Dulić T, Darienko T, Rybalka N, Friedl T (2016) Cyanobacteria and algae of biological soil crusts. In: Weber B, Büdel B, Belnap J (eds) Biological soil crusts: an organizing principle in drylands. Springer International Publishing, Cham, pp 5580

8. Pushkareva E, Johansen JR, Elster J (2016) A review of the ecology, ecophysiology and biodiversity of microalgae in Arctic soil crusts. Polar Biol 39:2227-2240. https://doi.org/10.1007/s00300016-1902-5

9. $\mathrm{Hu}$ C, Gao K, Whitton BA (2002) Semi-arid regions and deserts. In: Whitton BA (ed) Ecology of cyanobacteria II: their diversity in space and time. Springer, Dordrecht, pp 345-369

10. Knowles EJ, Castenholz RW (2008) Effect of exogenous extracellular polysaccharides on the desiccation and freezing tolerance of rock-inhabiting phototrophic microorganisms. FEMS Microbiol Ecol 66:261-270. https://doi.org/10.1111/j.1574-6941.2008. 00568.x

11. Castenholz RW, Garcia-Pichel F (2002) Cyanobacterial responses to UV radiation. In: Whitton BA (ed) Ecology of cyanobacteria II: their diversity in space and time. Springer, Dordrecht, pp 481-499

12. Yoshitake S, Uchida M, Koizumi H, Kanda H, Nakatsubo T (2010) Production of biological soil crusts in the early stage of primary succession on a High Arctic glacier foreland. New Phytol 186: 451-460. https://doi.org/10.1111/j.1469-8137.2010.03180.x

13. Breen K, Lévesque E (2006) Proglacial succession of biological soil crusts and vascular plants: biotic interactions in the High Arctic. Can J Bot 84:1714-1731. https://doi.org/10.1139/b06-131

14. Kwon HY, Jung JY, Kim O, Laffly D, Lim HS, Lee YK (2015) Soil development and bacterial community shifts along the chronosequence of the Midtre Lovénbreen glacier foreland in Svalbard. Ecol Environ 38:461-476. https://doi.org/10.5141/ ecoenv.2015.049

15. Bajerski F, Wagner D (2013) Bacterial succession in Antarctic soils of two glacier forefields on Larsemann Hills, East Antarctica. FEMS Microbiol Ecol 85:128-142. https://doi.org/10.1111/15746941.12105

16. Zumsteg A, Luster J, Göransson H, Smittenberg RH, Brunner I, Bernasconi SM, Zeyer J, Frey B (2012) Bacterial, archaeal and fungal succession in the forefield of a receding glacier. Microb Ecol 63:552-564. https://doi.org/10.1007/s00248-011-9991-8

17. Rime T, Hartmann M, Brunner I, Widmer F, Zeyer J, Frey B (2015) Vertical distribution of the soil microbiota along a successional gradient in a glacier forefield. Mol Ecol 24:1091-1108. https:// doi.org/10.1111/mec.13051

18. Rime T, Hartmann M, Frey B (2016) Potential sources of microbial colonizers in an initial soil ecosystem after retreat of an alpine glacier. ISME J 10:1625-1641. https://doi.org/10.1038/ismej. 2015.238

19. Nemergut DR, Anderson SP, Cleveland CC, Martin AP, Miller AE, Seimon A, Schmidt SK (2007) Microbial community succession in an unvegetated, recently deglaciated soil. Microb Ecol 53:110-122. https://doi.org/10.1007/s00248-006-9144-7

20. Schmidt SK, Reed SC, Nemergut DR, Grandy AS, Cleveland CC, Weintraub MN, Hill AW, Costello EK, Meyer AF, Neff JC, Martin AM (2008) The earliest stages of ecosystem succession in highelevation (5000 metres above sea level), recently deglaciated soils. Proc R Soc B 275:2793-2802. https://doi.org/10.1098/rspb.2008. 0808
21. Turicchia S, Ventura S, Schütte U, Soldati E, Zielke M, Solheim B (2005) Biodiversity of the cyanobacterial community in the foreland of the retreating glacier Midtre Lovènbreen, Spitsbergen, Svalbard. Algol Stud 117:427-440. https://doi.org/10.1127/18641318/2005/0117-0427

22. Frey B, Bühler L, Schmutz S, Zumsteg A, Furrer G (2013) Molecular characterization of phototrophic microorganisms in the forefield of a receding glacier in the Swiss Alps. Environ Res Lett 8:15033. https://doi.org/10.1088/1748-9326/8/1/015033

23. Roesch LFW, Fulthorpe RR, Riva A, Casella G, Hadwin AKM, Kent AD, Daroub SH, FAO C, Farmerie GW, Triplett EW (2007) Pyrosequencing enumerates and contrasts soil microbial diversity. ISME J 1:283-290. https://doi.org/10.1038/ismej.2007.53

24. Klindworth A, Pruesse E, Schweer T, Peplies J, Quast C, Horn M, Glöckner FO (2013) Evaluation of general 16S ribosomal RNA gene PCR primers for classical and next-generation sequencingbased diversity studies. Nucleic Acids Res 41:e1. https://oi.org/ 10.1093/nar/gks808

25. Pushkareva E, Pessi IS, Wilmotte A, Elster J (2015) Cyanobacterial community composition in Arctic soil crusts at different stages of development. FEMS Microbiol Ecol 91:fiv143. https://doi.org/10. 1093/femsec/fiv143

26. Pessi IS, Maalouf PC, Laughinghouse IV HD, Baurain D, Wilmotte A (2016) On the use of high-throughput sequencing for the study of cyanobacterial diversity in Antarctic aquatic mats. J Phycol 52: 356-368. https://doi.org/10.1111/jpy.12399

27. Pessi IS, Lara Y, Durieu B, Maalouf PC, Verleyen E, Wilmotte A (2018) Community structure and distribution of benthic cyanobacteria in Antarctic lacustrine microbial mats. FEMS Microbiol Ecol 94:fiy042. https://doi.org/10.1093/femsec/fiy042

28. Pushkareva E, Pessi IS, Namsaraev Z, Mano M-J, Elster J, Wilmotte A (2018) Cyanobacteria inhabiting biological soil crusts of a polar desert: Sør Rondane Mountains, Antarctica. Syst Appl Microbiol https://doi.org/10.1016/j.syapm.2018.01.006

29. ACIA (2005) Arctic climate impact assessment. Cambridge University Press, Cambridge

30. Láska K, Witoszová D, Prošek P (2012) Weather patterns of the coastal zone of Petuniabukta, central Spitsbergen in the period 2008-2010. Pol Polar Res 33:297-318. https://doi.org/10.2478/ v10183-012-0025-0

31. Szczuciński W, Rachlewicz G (2007) Geological setting of the Petuniabukta region. Landf Anal 5:212-215

32. Rachlewicz G, Szczuciński W, Ewertowski M (2007) Post-'Little Ice Age' retreat rates of glaciers around Billefjorden in central Spitsbergen, Svalbard. Pol Polar Res 28:159-186

33. Hillebrand H, Dürselen C-D, Kirschtel D, Pollingher U, Zohary T (1999) Biovolume calculation for pelagic and benthic microalgae. J Phycol 35:403-424. https://doi.org/10.1046/j.1529-8817.1999. 3520403.x

34. Nübel U, Garcia-Pichel F, Muyzer G (1997) PCR primers to amplify 16S rRNA genes from cyanobacteria. Appl Environ Microbiol 63:3327-3332

35. Edgar RC (2013) UPARSE: highly accurate OTU sequences from microbial amplicon reads. Nat Methods 10:996-998. https://doi. org/10.1038/nmeth.2604

36. Taton A, Grubisic S, Brambilla E, De Wit R, Wilmotte A (2003) Cyanobacterial diversity in natural and artificial microbial mats of Lake Fryxell (McMurdo dry valleys, Antarctica): a morphological and molecular approach. Appl Environ Microbiol 69:5157-5169. https://doi.org/10.1128/AEM.69.9.5157-5169.2003

37. Lanzén A, Jørgensen SL, Huson DH, Gorfer M, Grindhaug SH, Jonassen I, Øvreås L, Urich T (2012) CREST — classification resources for environmental sequence tags. PLoS One 7:e49334. https://doi.org/10.1371/journal.pone.0049334

38. McDonald D, Price MN, Goodrich J, Nawrocki EP, DeSantis TZ, Probst A, Andersen GL, Knight R, Hugenholtz P (2012) An 
improved Greengenes taxonomy with explicit ranks for ecological and evolutionary analyses of bacteria and archaea. ISME J 6:610 618. https://doi.org/10.1038/ismej.2011.139

39. Hoffmann L, Komárek J, Kaštovský (2005) System of cyanoprokaryotes (cyanobacteria) - state in 2004. Algol Stud 117:95-115. https://doi.org/10.1127/1864-1318/2005/0117-0095

40. Lozupone C, Knight R (2005) UniFrac: a new phylogenetic method for comparing microbial communities. Appl Environ Microbiol 71: 8228-8235. https://doi.org/10.1128/aem.71.12.8228-8235.2005

41. Caporaso JG, Kuczynski J, Stombaugh J, Bittinger K, Bushman FD, Costello EK, Fierer N, Peña AG, Goodrich JK, Gordon JI, Huttley GA, Kelley ST, Knights D, Koenig JE, Ley RE, Lozupone CA, McDonald D, Muegge BD, Pirrung M, Reeder J, Sevinsky JR, Turnbaugh PJ, Walters WA, Widmann J, Yatsunenko T, Zaneveld J, Knight R (2010) QIIME allows analysis of highthroughput community sequencing data. Nat Methods 7:335-336. https://doi.org/10.1038/nmeth.f.303

42. Anderson MJ (2001) A new method for non-parametric multivariate analysis of variance. Austral Ecol 26:32-46. https://doi.org/10. 1111/j.1442-9993.2001.01070.pp.x

43. Anderson MJ, Willis TJ (2003) Canonical analysis of principal coordinates: a useful method of constrained ordination for ecology. Ecology 84:511-525. https://doi.org/10.1890/0012-9658(2003) 084[0511:CAOPCA]2.0.CO;2

44. Peres-Neto PR, Legendre P, Dray S, Borcard D (2006) Variation partitioning of species data matrices: estimation and comparison of fractions. Ecology 87:2614-2625. https://doi.org/10.1890/00129658(2006)87[2614:VPOSDM]2.0.CO;2

45. Edgar RC (2004) MUSCLE: multiple sequence alignment with high accuracy and high throughput. Nucleic Acids Res 32:17921797. https://doi.org/10.1093/nar/gkh340

46. Kumar S, Stecher G, Tamura K (2016) MEGA7: molecular evolutionary genetics analysis version 7.0 for bigger datasets. Mol Biol Evol 33:1870-1874. https://doi.org/10.1093/molbev/msw054

47. Taton A, Grubisic S, Ertz D, Hodgson DA, Piccardi R, Biondi N, Tredici MR, Mainini M, Losi D, Marinelli F, Wilmotte A (2006) Polyphasic study of Antarctic cyanobacterial strains. J Phycol 42: 1257-1270. https://doi.org/10.1111/j.1529-8817.2006.00278.x

48. Martineau E, Wood SA, Miller MR, Jungblut AD, Hawes I, Webster-Brown J, Packer MA (2013) Characterisation of Antarctic cyanobacteria and comparison with New Zealand strains. Hydrobiologia 711:139-154. https://doi.org/10.1007/s10750-0131473-1

49. Bosak T, Liang B, Sim MS, Petroff AP (2009) Morphological record of oxygenic photosynthesis in conical stromatolites. Proc Natl Acad Sci U S A 106:10939-10943. https://doi.org/10.1073/pnas. 0900885106

50. Lopes VR, Ramos V, Martins A, Sousa M, Welker M, Antunes A, Vasconcelos VM (2012) Phylogenetic, chemical and morphological diversity of cyanobacteria from Portuguese temperate estuaries. Mar Environ Res 73:7-16. https://doi.org/10.1016/j.marenvres. 2011.10.005

51. Saw JHW, Schatz M, Brown MV, Kunkel DD, Foster JS, Shick H, Christensen S, Hou S, Wan X, Donachie SP (2013) Cultivation and complete genome sequencing of Gloeobacter kilaueensis sp. nov., from a lava cave in Kīlauea Caldera, Hawai'i. PLoS One 8:e76376. https://doi.org/10.1371/journal.pone.0076376

52. Hanson CA, Fuhrman JA, Horner-Devine MC, Martiny JBH (2012) Beyond biogeographic patterns: processes shaping the microbial landscape. Nat Rev Microbiol 10:497-506. https:/doi. org/10.1038/nrmicro2795

53. Schulz S, Brankatschk R, Dümig A, Kögel-Knabner I, Schloter M, Zeyer J (2013) The role of microorganisms at different stages of ecosystem development for soil formation. Biogeosciences 10: 3983-3996. https://doi.org/10.5194/bg-10-3983-2013

54. Gaget V, Keulen A, Lau M, Monis P, Brookes JD (2016) DNA extraction from benthic cyanobacteria: comparative assessment and optimization. J Appl Microbiol 122:294-304. https://doi.org/ 10.1111/jam.13332

55. Wilmotte A, Golubić S (1991) Morphological and genetic criteria in the taxonomy of Cyanophyta/cyanobacteria. Algol Stud 64:1-24

56. Fierer N, Nemergut DR, Knight R, Craine JM (2010) Changes through time: integrating microorganisms into the study of succession. Res Microbiol 161:635-642. https://doi.org/10.1016/j.resmic. 2010.06.002

57. Chrismas NAM, Barker G, Anesio AM, Sánchez-Baracaldo P (2016) Genomic mechanisms for cold tolerance and production of exopolysaccharides in the Arctic cyanobacterium Phormidesmis priestleyi BC1401. BMC Genomics 17:533. https://doi.org/10. 1186/s12864-016-2846-4

58. Lara Y, Durieu B, Cornet L, Verlaine O, Rippka R, Pessi IS, Misztak A, Joris B, Javaux EJ, Baurain D, Wilmotte A (2017) Draft genome sequence of the axenic strain Phormidesmis priestleyi ULC007, a cyanobacterium isolated from Lake Bruehwiler (Larsemann Hills, Antarctica). Genome Announc 5: e01546-e01516. https://doi.org/10.1128/genomea.01546-16

59. Edwards A, Anesio AM, Rassner SM, Sattler B, Hubbard B, Perkins WT, Young M, Griffith GW (2011) Possible interactions between bacterial diversity, microbial activity and supraglacial hydrology of cryoconite holes in Svalbard. ISME J 5:150-160. https:// doi.org/10.1038/ismej.2010.100

60. Anesio AM, Laybourn-Parry J (2012) Glaciers and ice sheets as a biome. Trends Ecol Evol 27:219-225. https://doi.org/10.1016/j. tree.2011.09.012

61. Vonnahme TR, Devetter M, Žárský JD, Šabacká M, Elster J (2016) Controls on microalgal community structures in cryoconite holes upon high-Arctic glaciers, Svalbard. Biogeosciences 13:659-674. https://doi.org/10.5194/bg-13-659-2016

62. Hodson A, Anesio AM, Tranter M, Fountain A, Mark O, Priscu J, Laybourn-Parry J, Sattler B (2008) Glacial ecosystems. Ecol Monogr 78:41-67. https://doi.org/10.1890/07-0187.1

63. Freedman Z, Zak DR (2015) Soil bacterial communities are shaped by temporal and environmental filtering: evidence from a long-term chronosequence. Environ Microbiol 17:3208-3218. https://doi.org/ 10.1111/1462-2920.12762

64. Chapin FS, Walker LR, Fastie CL, Sharman LC (1994) Mechanisms of primary succession following deglaciation at Glacier Bay, Alaska. Ecol Monogr 64:149-175. https://doi.org/ $10.2307 / 2937039$

65. Crocker RL, Major J (1955) Soil development in relation to vegetation and surface age at Glacier Bay, Alaska. J Ecol 43:427-448

66. Sigler WV, Crivii S, Zeyer J (2002) Bacterial succession in glacial forefield soils characterized by community structure, activity and opportunistic growth dynamics. Microb Ecol 44:306-316. https:// doi.org/10.1007/s00248-002-2025-9

67. Sigler WV, Zeyer J (2004) Colony-forming analysis of bacterial community succession in deglaciated soils indicates pioneer stress-tolerant opportunists. Microb Ecol 48:316-323. https://doi. org/10.1007/s00248-003-0189-6 